\title{
馬體諸測定值の相關々係
}

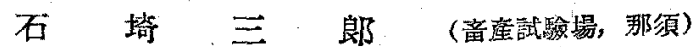

Studies on correlation" between various measures of physical

characters of the body in the horse.

SABURO ISHIZAKI

(Imperial Zootechnical Experiment Station, Nasu)

I·諸 , 言

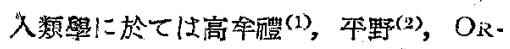
ENSTEEN $^{(3)}$ との他により人體測定值の相

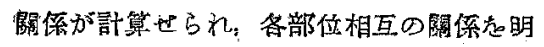
らかにこ，人種差に就ても覦及せられて居

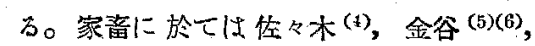
ZENTNER(7), GREGORY ${ }^{(8)}$ 等によv牛體

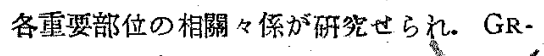

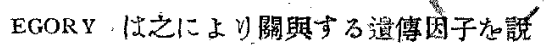

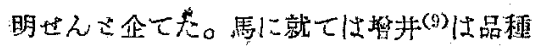
别國有程馬の髏高飞他の部位間に概久正の 相關の存在す事家證し，又主要小及部位

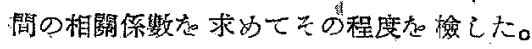
馬體各部の關係は份從來相默上之りる色名 そ云タせられてるかが，之等は主として經 驗によりたる゙すにこて磪たる基䃈危有す るるのそば言ひ碓い。

本調楂は我國々有種牡䭴の體重，䯣高， 胸園，管園等と他の諸部位この關係㤂考然

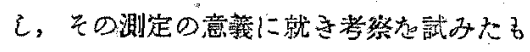

のである。材料瑪は東北地方及び北海道の各種馬場所に

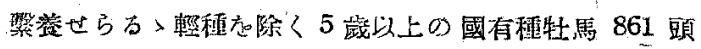
(體重關係にありては 672 㖽)にして，昭和 17 年 12 月

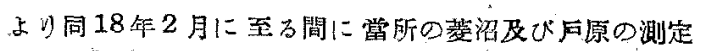
ぜるまのであ。

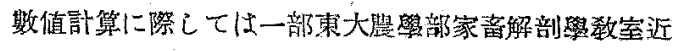

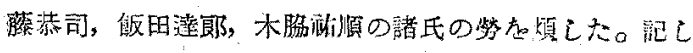
て感射の意起表する。

\section{II 各部位間相關你數}

各部位闆相關係数算出するに第 1 表の如くである。

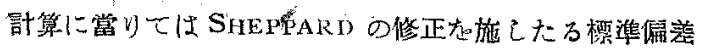
苞朋ひた。
第1表备部位問相關係数表

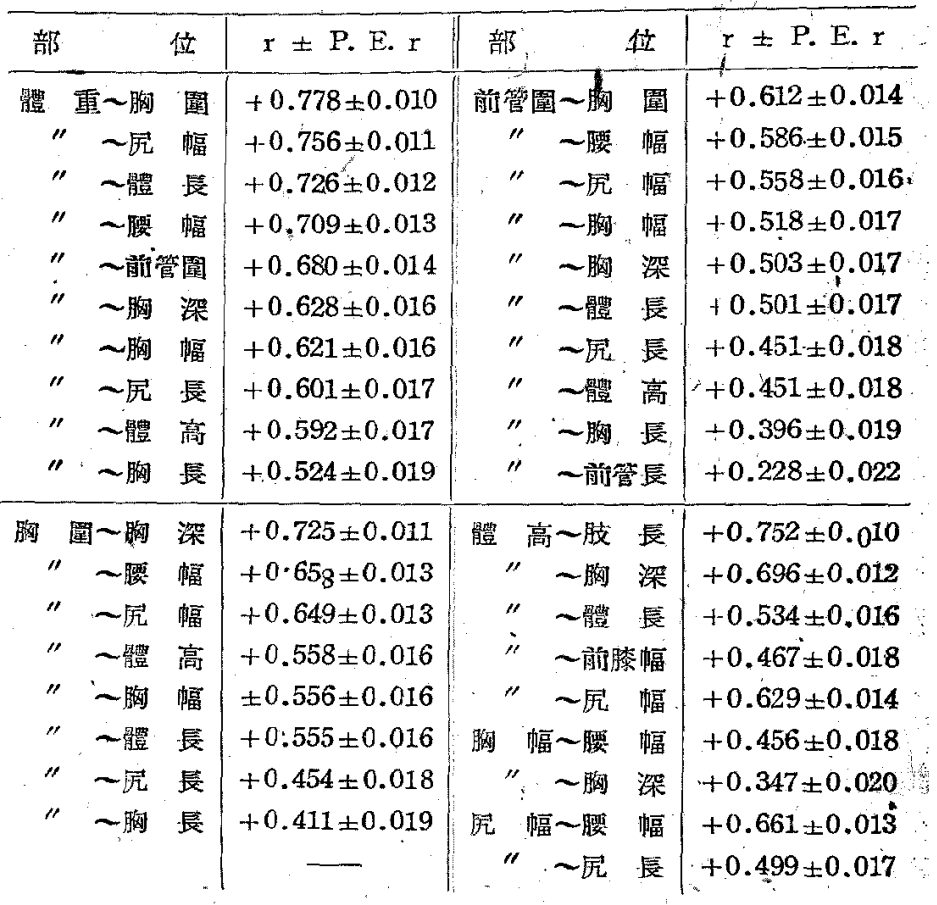

之等の相關係數の有意性走 R. A. FISHER の F一分 布(10)(II)により检定する゙に何れも有意である。

相閔係数に基き䭴體各部位の關係地考祭するに次の如 くでおる。

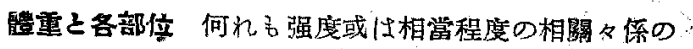

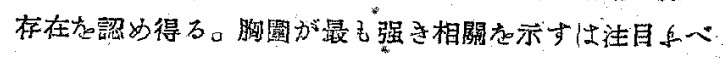

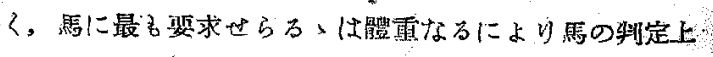

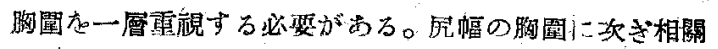

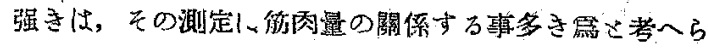

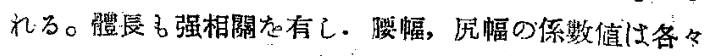
䯘幅の體重に關係する事多き九示し，胸深のえれは胸圍

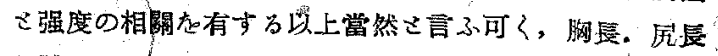

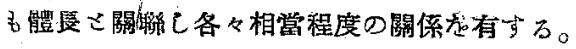




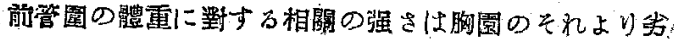
るる體高のそれより厔り略その中間に位する。體高は他 の部位に比で能重之關係する票比較的小でする。

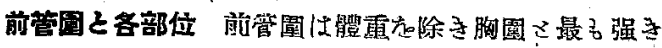
關係を有し他の部位さは概れ相賞程度の相關であるが， 前管唇さは弱相關である。體重さは强相關老有ずる（前

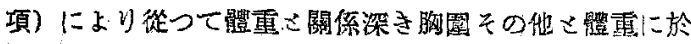

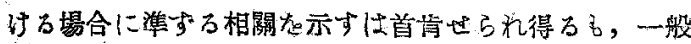

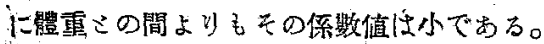

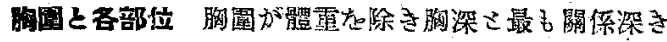
はその權成分子なるにより當然なるも胸幅に於りるより

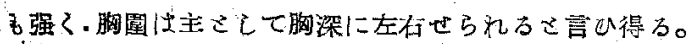

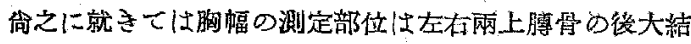
節䦔の距離にして真の胸幅はをの後方に位し之龙表はき くる鹪をる考へられるのである。胸園は前管園に於讨る 堨合を等しく體重さ關係おる他の各部位々の間に於て略 體電に準ずる關係危有するる，體高，體長とは略同程度 の相關起有するが異れる點である。

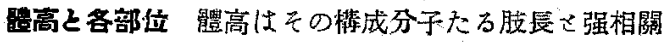

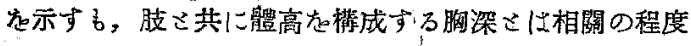
之に劣り，體高は肢長に影響せられる事多こて言ひ得る。

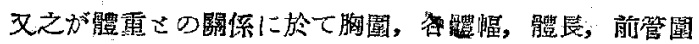
等よりその相關程度忩方理由さ考へられる。然れごも顝

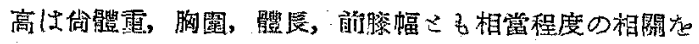
有与方。

その他の各部垃間 胸幅さ胃幅, 胸幅さ腰幅の相關は

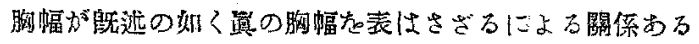

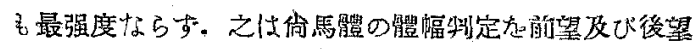
よりな与必要起示するのと考へられる。庁幅さ腰幅区の

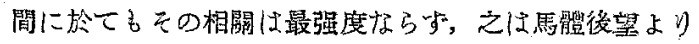

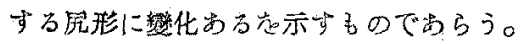

\section{III 相關比, 退行線の直線性の 检定，及び退行方程式}

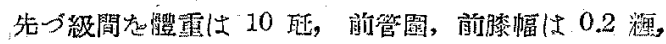

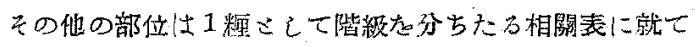
相關比 $(\eta)$ 起算出した。之の存意性尤相關係数に於りる 圽合こ同溙， $F$ 一分布により检定するに各々の有意なる 事は明ら加で尚方。

次に退行線の直線性を檢定ず方型相關比を” SHEPPARD の修正を䑨さざる標準偏差を细ひて計算ぜる相關係 數龙比較し、 $\eta^{2}-r^{2}$ 在求むる门第 2 表の如くである。

第 2 表退行線の直線性の檢定

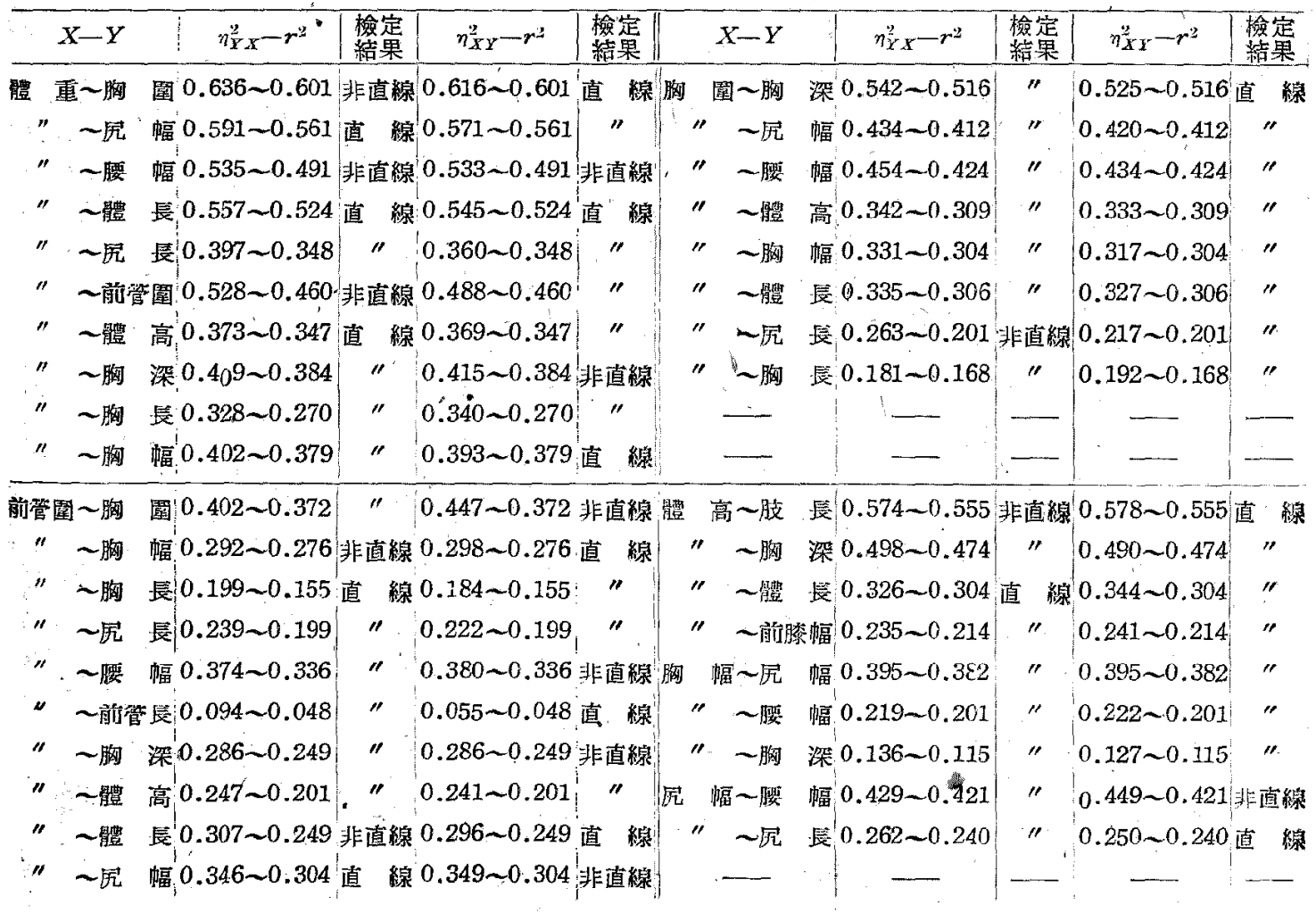




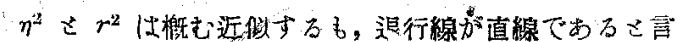
假設(12)总

$$
F_{0}=\frac{\eta^{2}-r^{2}}{1-\eta^{2}} \frac{N-k}{k-2} \quad \text { 位 } \quad \begin{aligned}
& N: \text { 絽數 } \\
& k \text { : 階級數 }
\end{aligned}
$$

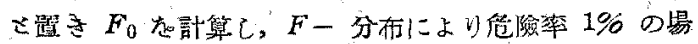
合の $F$ 起求み， $F_{0}$ が $F$ より大なるわ小なる中にり假

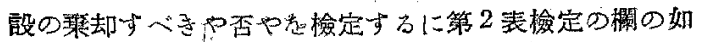
く，大部分の部位に於て直線已看做已得るる 1 部のもの に於ては淔線さ認的得导る結果走得た。相關比は階級の 區分の取り方により大小異にと，又測定頭数の多少，

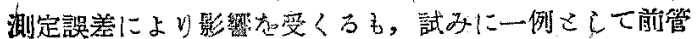

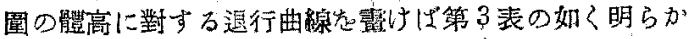

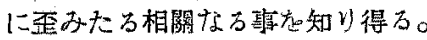

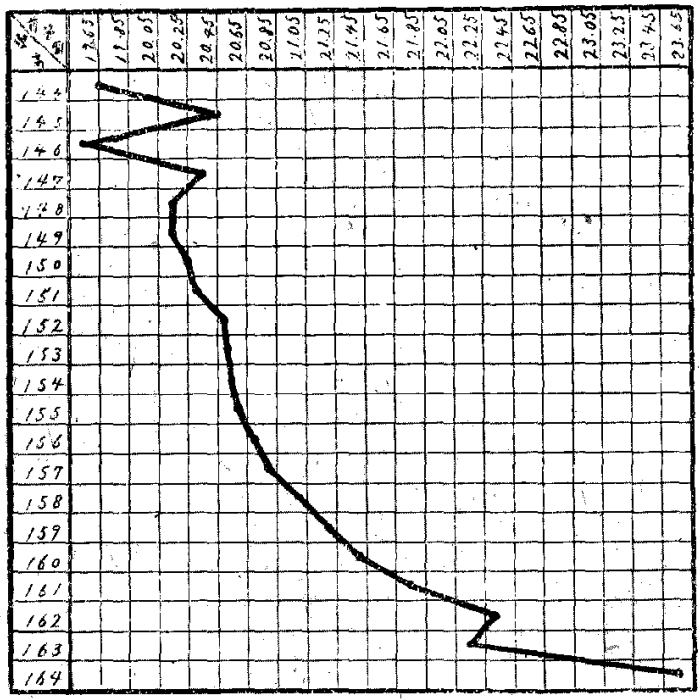

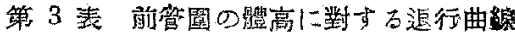

退行線の直線さ看做己得るものに就き退行方程式奆作 成さた。之を揭示するは炧雜なるにより之が作成に必裂 なる請能值即ち各々の平均值 $\left(M_{X}\right.$ 及び $\left.M_{X}\right)$ 绝に退行

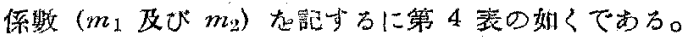

第 4 表：退行方程式作成に必要小万䜊數檤表

\begin{tabular}{|c|c|c|c|c|c|c|}
\hline$X$ & \multicolumn{2}{|c|}{$Y$} & $M_{x}$ & $M_{Y}$ & $m_{1}$ & $m_{2}$ \\
\hline 疆 & 電 月 & 囯 & 584.568 & 186.638 & 6.882 & - \\
\hline & $\sim$ & 䒇 & & 54.228 & 17.197 & 0.033 \\
\hline$"$ & ～䇾照 & 長 & $"$ & 161.699 & 6.355 & 0.083 \\
\hline 1 & ～前 & 筥園 & $" \prime$ & 20.885 & 33.447 & - \\
\hline / & ～脢 & 潍 & $"$ & $73 \quad 452$ & - & 0.031 \\
\hline " & 一胸 & 幅 & $"$ & 44.903 & 12.700 & 0.030 \\
\hline " & $\sim \mathrm{F}^{*}$ & 㹂 & $"$ & 50.324 & 14.241 & 0.025 \\
\hline " & ～䚟 & 鄗 & $"$ & 155.737 & 7.839 & 0.045 \\
\hline , & ～胸 & 長 & " & 97.573 & - & 0.041 \\
\hline
\end{tabular}

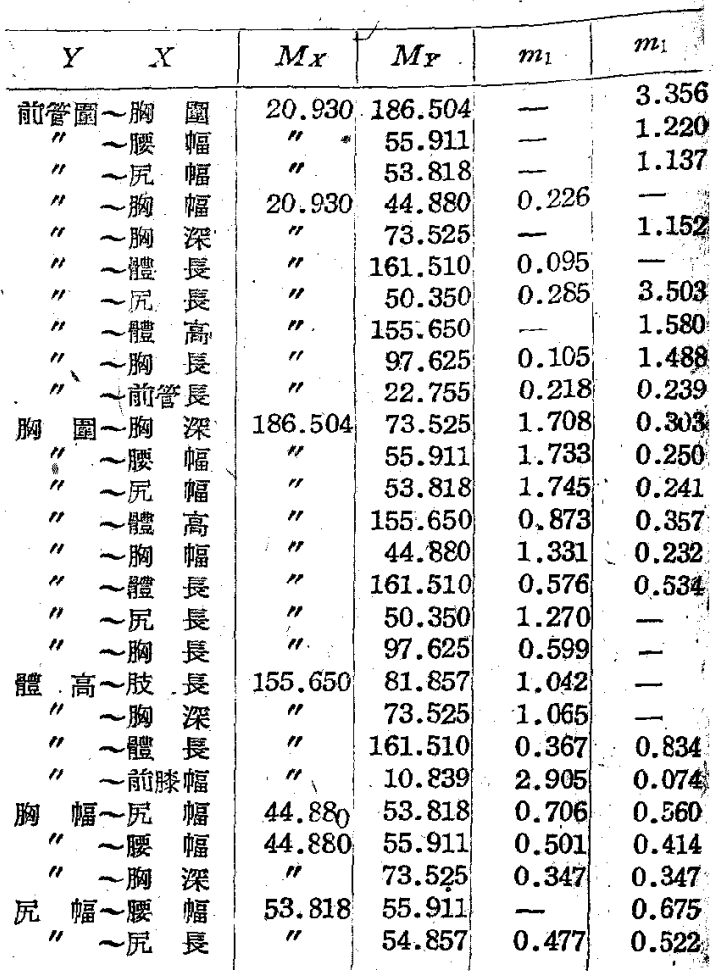

備考 $m_{1}=\frac{\bar{x}}{y}, \quad m_{2}=\frac{\bar{y}}{x}$ ¿す。

但し $\bar{x}: y$ の各階級丙での $x$ の算套平均 $\bar{y}: x$ の各階級间での $y$ の算街平均

\section{IV 部分相關係數}

既述の相籍係數は全相關係數にこて各部位間には多數 の相關因子の存在方゙考入られる。今此較的純粹に各部位

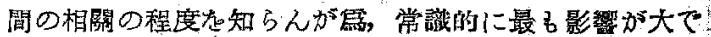

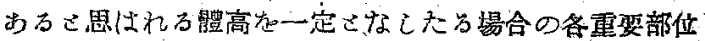
間の部分相關係斯起求むるに第 5 表の如くでおる。

第。5 表部分相關係數表

\begin{tabular}{|c|c|c|}
\hline 相 關 部 位 & $r \pm$ P. E. $r$ & 撤 㛄 \\
\hline 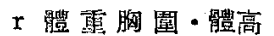 & $0.669 \pm 0.014$ & $*$ \\
\hline 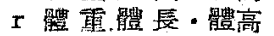 & $0.594 \pm 0.017$ & \\
\hline 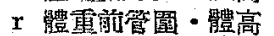 & $0.575 \pm 0.017$ & $*$ \\
\hline 工 體 甹胸 深 - 體高 & $0.373 \pm 0.022$ & * \\
\hline r 前壱園胸圍・體高 & $0.487 \pm 0.018$ & $*^{2}$ \\
\hline $\mathrm{r}$ 前管堛胸深・體商 & $0.295 \pm 0.021$ & * \\
\hline I 前管圍體長－體高 & $0.338 \pm 0.020$ & * \\
\hline r 胸瞄胸深・體高 & $0.565 \pm 0.016$ & \\
\hline 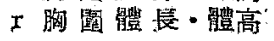 & $0.356 \pm 0.020$ & \\
\hline
\end{tabular}

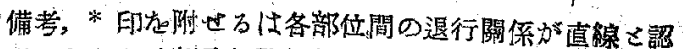

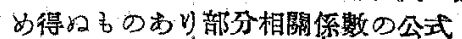

$$
r_{12 \cdot 3}=\frac{r_{12}-r_{13} r_{23}}{\sqrt{1-r_{13}}}
$$

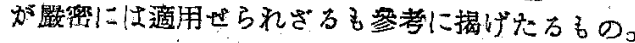




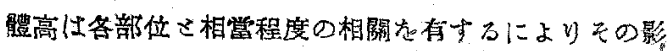

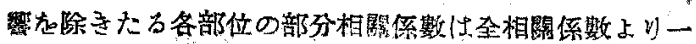

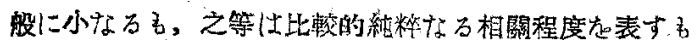
のを考へられる。

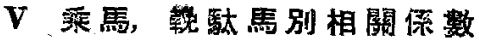 及びその比較}

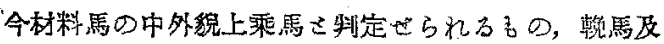

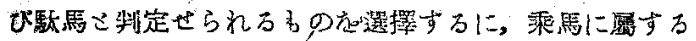

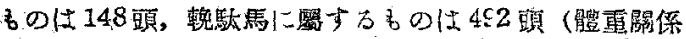

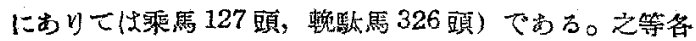
々の相關係數走算出ずるに第 5 琵の如くである。

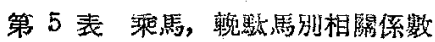
及ぴその比较

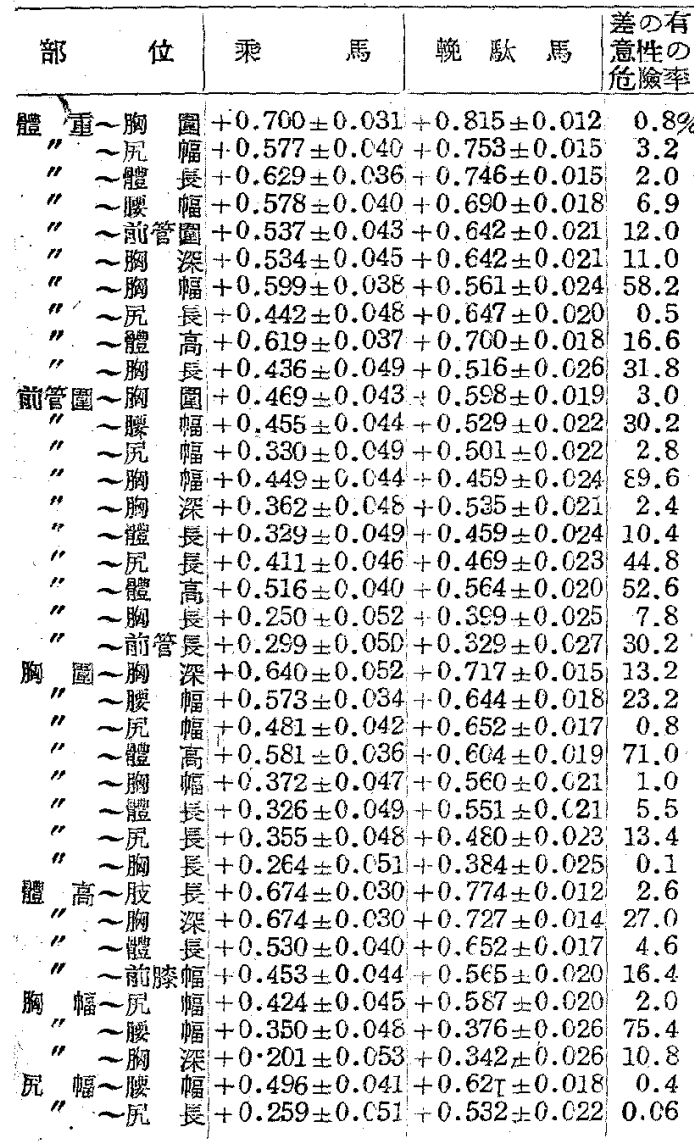

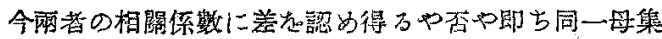

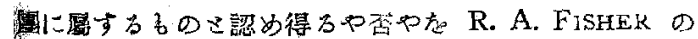
$Z$ 一紫換施用山

$$
t_{0}=\frac{Z_{1}-Z_{2}}{\sqrt{\frac{1}{n_{1}-3}+\frac{1}{n_{\sharp}-3}}} n: \text { 条辣の組數 }
$$

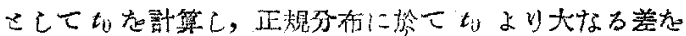

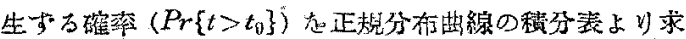

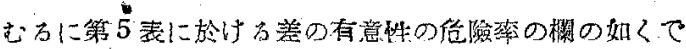

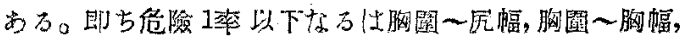

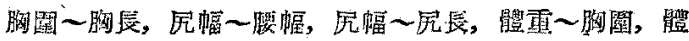

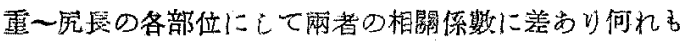

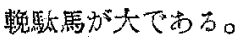

\section{VI 總一括}

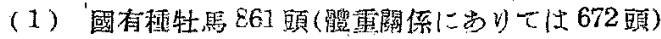

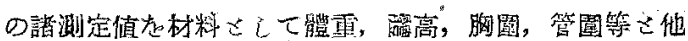
の各重留部位さの相閶々係㤂攻笑した。

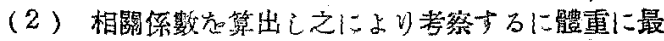

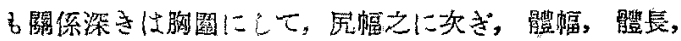

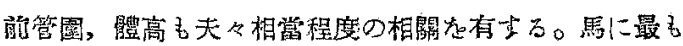

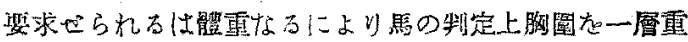

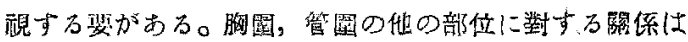
體重の天れらに對する場合飞略同樣であるが，係毁は一

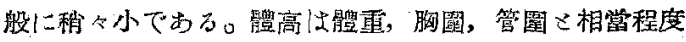

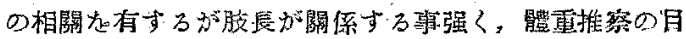
的よりすればその值值は胸圆，管園に少万るので岕る。

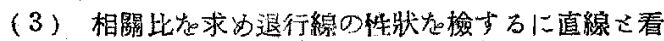

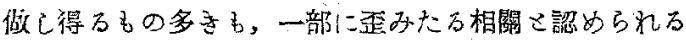
ものがある。

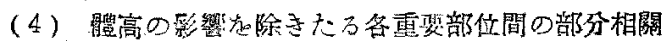

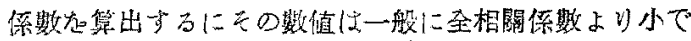

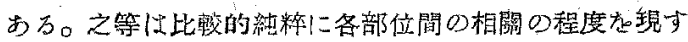
ものを考へられる。

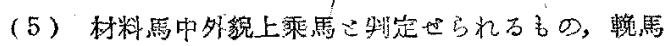

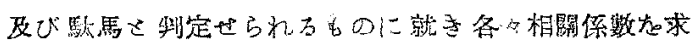
め，※の差起检したるに數っ部位に於て差の有意性走認

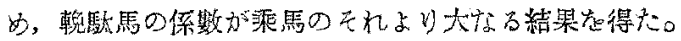

\section{女}

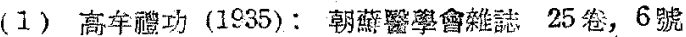
(2)，平野伍吉 $(1943)$ ：人類誌 58 织 6 號

(3) ORensteen, M. $(1915 \sim 1917)$ : Biometrika Vol. 11

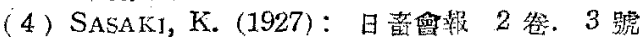

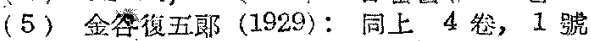

(6) 同 (1939): 同上4管，4號

(7) ZinNTNER, L. (1917): Diss. Bern. cit. by Kronacher's allg. Tierzucht. Abteil. 2, Aufl. 3, Anhang, Biometrika.

(8) GREGORY, P. W. (1933): Gentics Vol. 1, No. 8, P. 3.

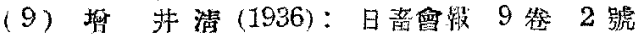

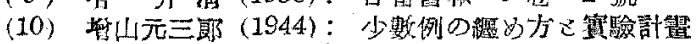
の立下方。籍 2 版 69 直

(11) Fisher, R. A: (1915): Biometrika Vol. 10.

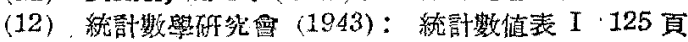

